\title{
All-Textile Corrugated Ground SIW Horn Antenna for Millimeter-Wave WBAN Applications
}

\author{
Seongkyu Lee $\cdot$ Jaehoon Choi ${ }^{*}$
}

\begin{abstract}
An all-textile H-plane substrate integrated waveguide (SIW) horn antenna for millimeter-wave wireless body area network applications is proposed. A coaxially fed SIW H-plane horn is designed for radiation toward a human body surface. To reduce the radiation to a human body and simultaneously increase the radiation to the human body surface, an extended corrugated ground is attached in front of the aperture of a horn. All components are made of textile materials. The simulated $10 \mathrm{~dB}$ return loss bandwidth is 2,400 $\mathrm{MHz}(26.7-29.1$ $\mathrm{GHz}$ ), which covers a potential candidate frequency band for $5 \mathrm{G}$ communication. The simulated and measured results show that the proposed antenna has a directional radiation pattern toward the body surface and a low power density below the antenna.
\end{abstract}

Key Words: Horn Antenna, Military Applications, Substrate Integrated Waveguide, Surface Wave Antenna, Textiles, Wearable.

\section{INTRODUCTION}

Communication systems using millimeter waves have received much attention in wireless body area networks (WBANs) because of their ultra-reliability, high speed, and low latency characteristics [1-3]. To establish good on-body communication linking body-mounted devices with a millimeter wave, an antenna with a directional radiation pattern toward the body surface is commonly used to compensate for the high path loss [4]. The $\mathrm{H}$-plane substrate integrated waveguide (SIW) horn antenna is a promising candidate for such applications because of its directional radiation pattern and low-profile characteristics. Many different technologies for such SIW horn antennas have been proposed to improve their performance. A printed transition, a pair of slots, and mushroom-type meta-materials have been placed in front of the SIW horn aperture to improve the radiation and match- ing performances [5-7]. However, such antennas have substantial radiation toward the human body. In the millimeterwave frequency band, the Federal Communications Commission (FCC) and International Commission on NonIonizing Radiation Protection (ICNIRP) regulate electromagnetic exposure through power density $[8,9]$. The power density limit is $10 \mathrm{~W} / \mathrm{m}^{2}$, and meeting this regulation at millimeter-wave frequencies is challenging. As a result, the input power of the antenna is limited, thus addressing the overall system power budget problem [10, 11]. Aiming to suppress radiation toward the body surface, a SIW H-plane horn antenna with an extended ground with a meta-surface and a large conducting plane was proposed [12, 13]. However, the extended ground and large conducting plane make the radiation beam pattern of the antenna tilted toward the broadside.

In this paper, an all-textile H-plane SIW horn antenna with corrugated ground is proposed for on-body WBAN

Manuscript received January 26, 2019 ; Revised May 1, 2019 ; Accepted May 27, 2019. (ID No. 20190126-006J)

Department of Electronics and Communications Engineering, Hanyang University, Seoul, Korea.

"Corresponding Author: Jaehoon Choi (e-mail: choijh@hanyang.ac.kr)

This is an Open-Access article distributed under the terms of the Creative Commons Attribution Non-Commercial License (http://creativecommons.org/licenses/by-nc/4.0) which permits unrestricted non-commercial use, distribution, and reproduction in any medium, provided the original work is properly cited.

(c) Copyright The Korean Institute of Electromagnetic Engineering and Science. 
applications. The proposed textile antenna operates at 28 $\mathrm{GHz}$, which is a potential frequency band for $5 \mathrm{G}$ millimeterwave communications. An extended corrugated ground is placed in front of a traditional SIW H-plane horn antenna (TSHA). The extended ground is used to suppress radiation toward the body surface. Corrugation is implemented on the extended ground to solve the beam tilting issue by utilizing its wave guiding characteristics $[14,15]$. The extended ground corrugation acts as an inductively reactive surface, creating a directional radiation pattern toward the near surface direction $\left(\theta=90^{\circ}\right)$ and reducing the radiation toward a human body. All antenna elements are fabricated using textile materials, such as conductive fabric, conductive thread, and textile substrates, because they are flexible and easily embedded into clothing.

\section{ANTENNA DESIGN}

Fig. 1 shows the geometry of the proposed antenna. The overall dimensions are $10 \mathrm{~mm} \times 24.5 \mathrm{~mm} \times 2.5 \mathrm{~mm}$. A felt fabric $\left(\varepsilon_{r}=1.2\right)$ with a thickness of $2.5 \mathrm{~mm}$ is used as the substrate. The proposed antenna is composed of a coaxially fed TSHA for generating a surface wave and an extended corrugated ground for guiding the wave towards the near surface direction $\left(\theta=90^{\circ}\right)$. The corrugation is realized by six walls with a height of $1.3 \mathrm{~mm}$ separated by a distance of 1.4 $\mathrm{mm}$. The top plane and ground plane of the SIW H-plane horn and the extended ground are made of conductive fabric $(\sigma=500,000 \mathrm{~S} / \mathrm{m})$. Conductive thread $(\sigma=20,000 \mathrm{~S} / \mathrm{m})$ with a radius of $0.2 \mathrm{~mm}$ is used for the via.

\section{SIMULATED RESULTS AND ANALYSIS}

To analyze the effect of the corrugations on the radiation

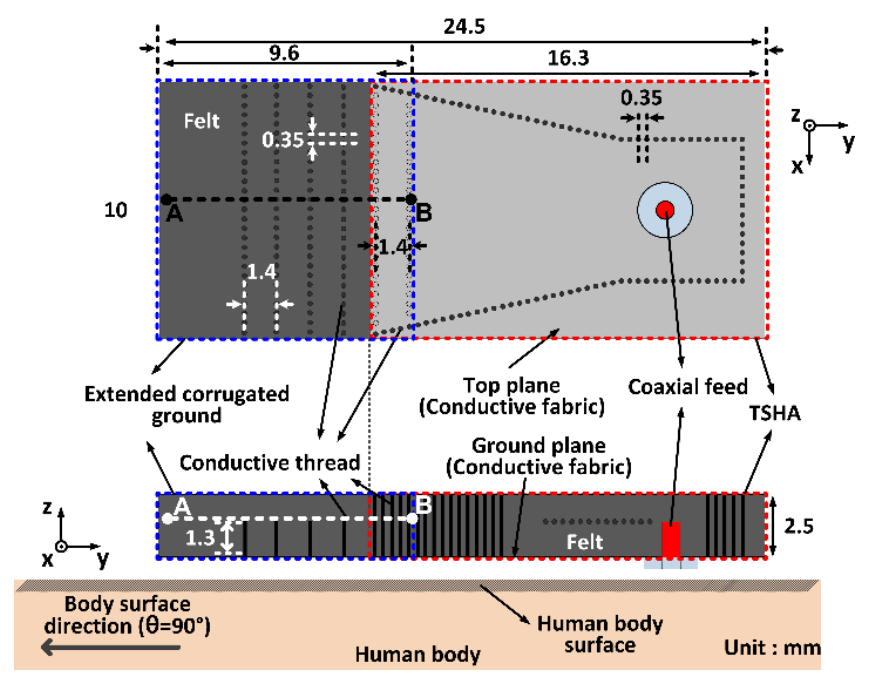

Fig. 1. Geometry of the proposed antenna. properties, the peak gain and gain toward the body surface direction $\left(\theta=90^{\circ}\right)$ are simulated for the different numbers of corrugations $(\mathrm{N})$ and height of corrugations $(\mathrm{H})$. The real and imaginary parts of the wave impedance $(\operatorname{Re}[Z]$ and $\operatorname{Im}[Z]$, respectively) are averaged in the line above the corrugation walls (A-B in Fig. 1). Fig. 2(a) and (b) show the trend of the gain and average impedance for the different $N$ and $H$ values. As the height of the corrugations increases, the corrugated surface becomes an inductively reactive surface, leading the surface wave to be bounded to a corrugated surface [16]. Although the average value of $\operatorname{Im}[Z]$ increases up to $H$ $=2 \mathrm{~mm}$, the gain toward the body surface direction $\left(\theta=90^{\circ}\right)$ has a peak value of $H=1.3 \mathrm{~mm}$, and it decreases beyond $H$ $=1.3 \mathrm{~mm}$ because of the impedance mismatching between the corrugation wall and the aperture of TSHA. The average value of $\operatorname{Im}[Z]$ increases with more corrugations being implemented on the extended ground and is not significantly changed after $N=4$. The gain toward the body surface direction $\left(\theta=90^{\circ}\right)$ has a similar trend on the average value of $\operatorname{Im}[Z]$. The peak gain is nearly constant for different $N$ values, with a maximum of $8.25 \mathrm{dBi}$ and a minimum of 7.53 dBi. Fig. 2(c) and (d) show the return loss characteristics and the E-plane radiation patterns of the TSHA, TSHA with extended ground $(N=0)$, and TSHA with corrugated ground $(N=6)$. Fig. $2(\mathrm{c})$ shows that the return loss characteristics improve when the ground of TSHA is extended and become even better with corrugation. The simulated $10 \mathrm{~dB}$ return loss bandwidth of the proposed antenna is $2,400 \mathrm{MHz}$ (26.7-29.1 GHz). In Fig. 2(d), the proposed antenna has an improved gain of $6.17 \mathrm{dBi}$ toward the body surface direction $\left(\theta=90^{\circ}\right)$ in comparison with the other cases (TSHA $=4.33$ $\mathrm{dBi}$; TSHA with extended ground $=3.9 \mathrm{dBi}$ ). The peak gains of TSHA, TSHA with extended ground, and TSHA with corrugated ground are $5.06 \mathrm{dBi}$ at $\theta=109^{\circ}, 7.93 \mathrm{dBi}$ at $\theta=46^{\circ}$, and $7.9 \mathrm{dBi}$ at $\theta=61^{\circ}$, respectively. For a practical on-body situation, the effect of bending the antenna should be considered. To investigate the effect of bending on the antenna performance, the antenna is bent along a cylinder with various radii $(r=15,25,100$, and 1,000 mm). Fig. 2(e) and (f) show the simulated return loss and radiation characteristics of the proposed antenna for various bending setups. Although the antenna is bent, the $10 \mathrm{~dB}$ return loss bandwidth remains stable and is sufficient to cover the $28 \mathrm{GHz}$ band. The bent antenna has a radiation pattern tilted in the direction along the end edge of the antenna. As the antenna consists of waveguide structures, the performance of the antenna is not severely affected by bending. Fig. 3(a)-(f) illustrate the simulated electric field distributions in the yz-plane. A substantial amount of the E-field propagates toward a body surface in Fig. 3(a). In Fig. 3(b), the E-field distribu- 


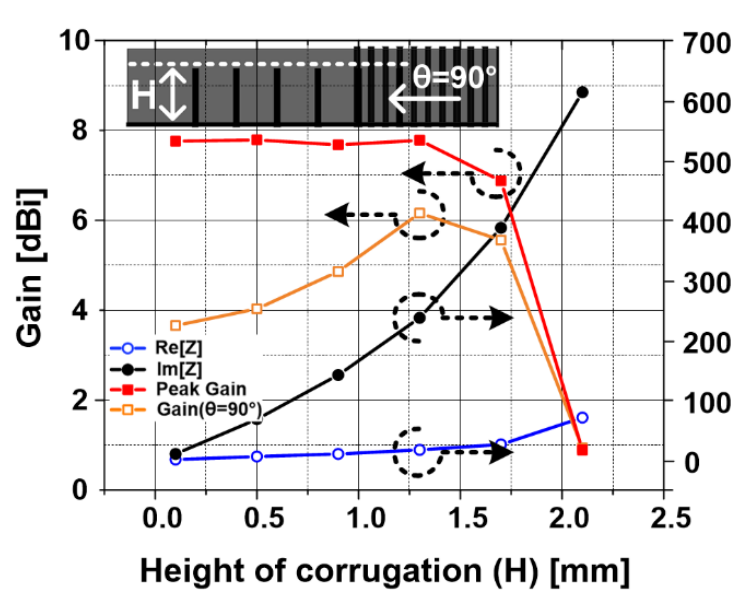

(a)

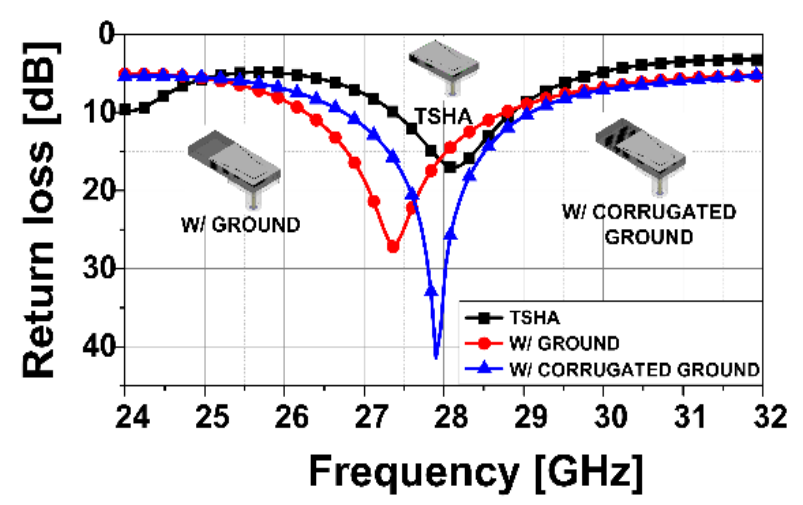

(c)

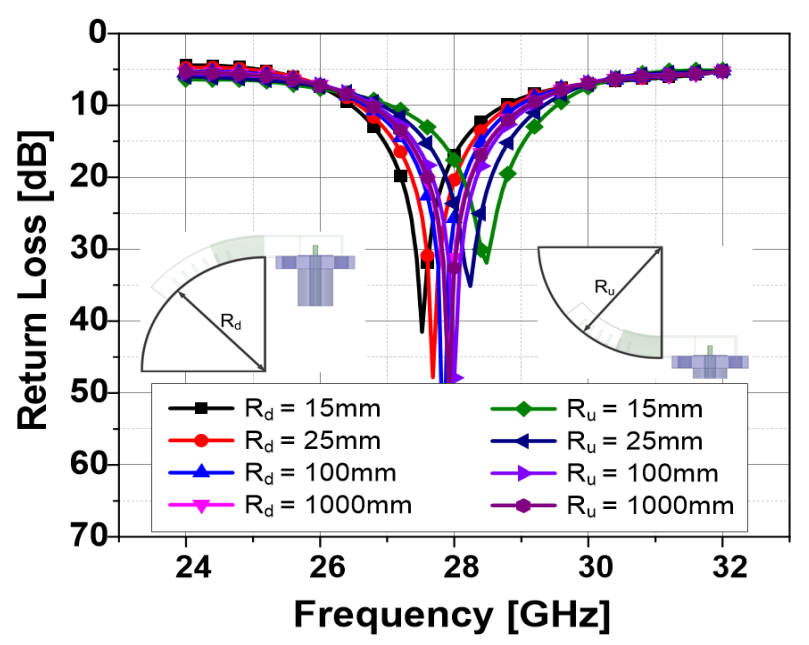

(e)

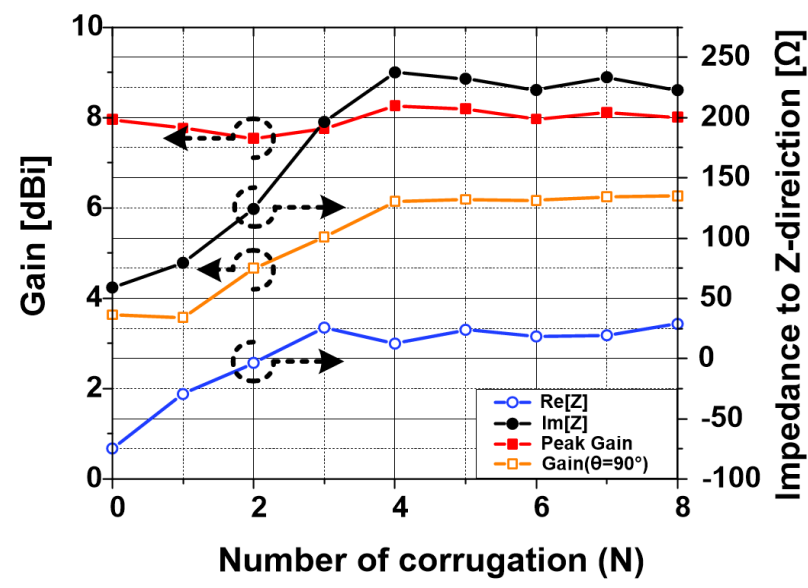

(b)

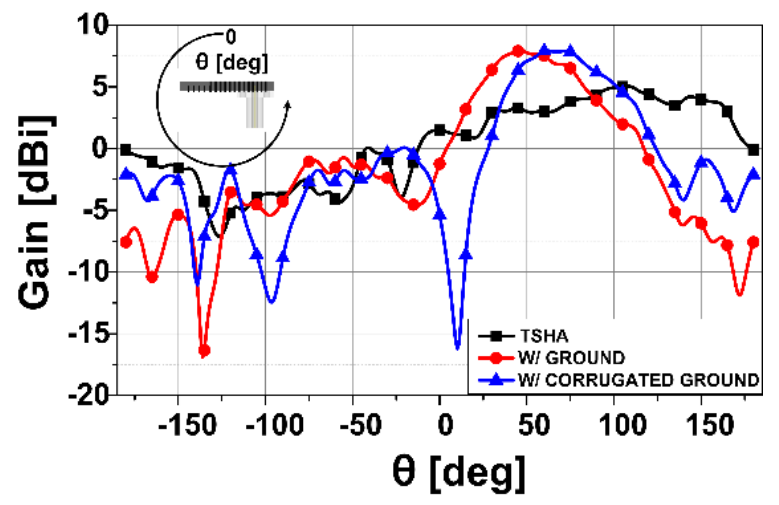

(d)

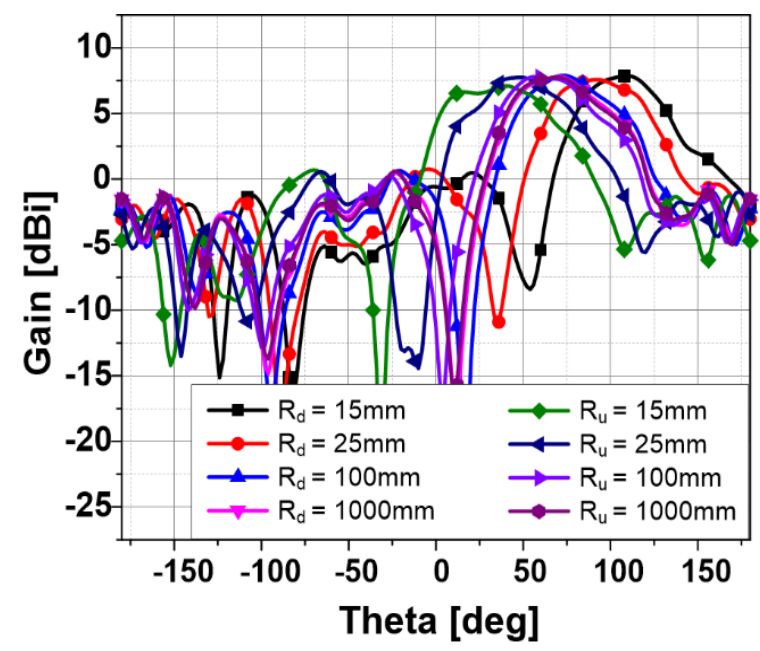

(f)

Fig. 2. Simulated results: (a) gain and wave impedance in the $\mathrm{z}$-direction for the different values of $N$, (b) gain and wave impedance in the $z$-direction for the different values of $H$, (c) return loss characteristics of the three phases of the developing antenna, (d) gain of the three phases of the developing antenna in the yz-plane, (e) return loss characteristics of the proposed antenna bent along the yzplane, and (f) gain of the proposed antenna bent along the yz-plane.

tion of TSHA with the extended ground shows that the extended ground attached in front of the aperture obstructs the propagation of the E-field toward a body surface and reflects the field, thus making the main radiation direction tilted toward the broadside.
However, the simulated E-field distribution of TSHA with the corrugated ground in Fig. 3(c) shows that the fields are guided along the body surface direction $\left(\theta=90^{\circ}\right)$ by confining the field in the corrugated ground, which is inductively reactive at $28 \mathrm{GHz}$. Fig. 3(d) and (e) show that the corru- 


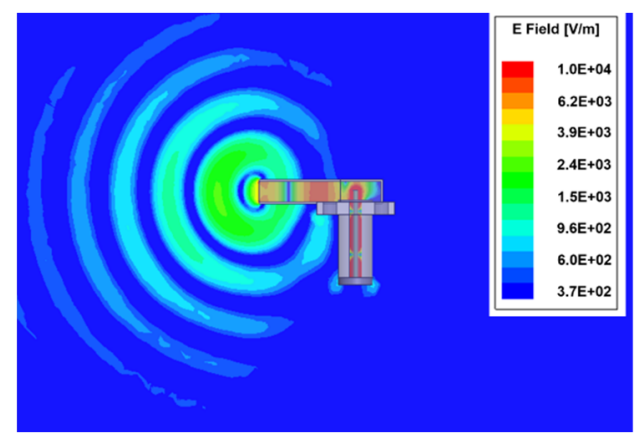

(a)

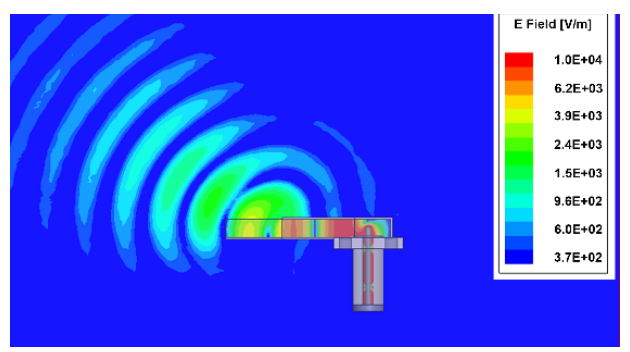

(b)

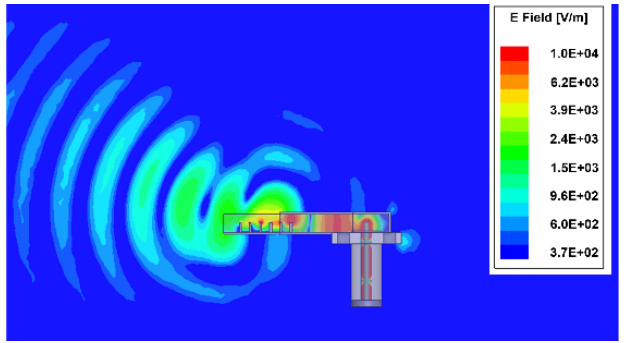

(c)

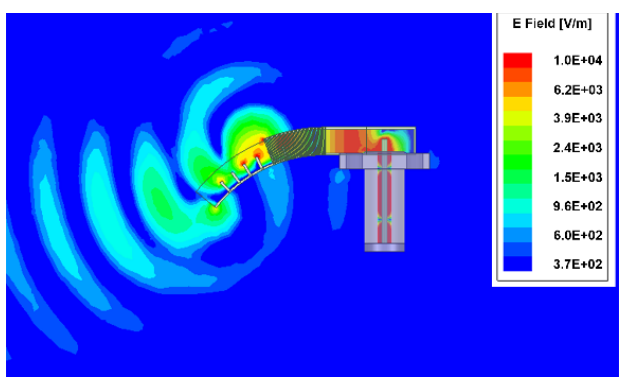

(d)

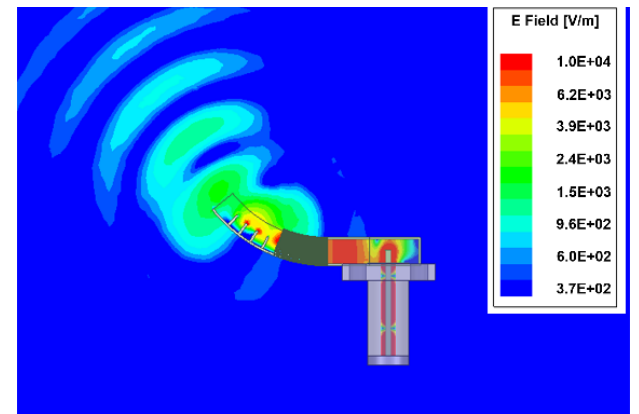

(e)

Fig. 3. Simulated electric field magnitude distributions in the yzplane: (a) TSHA, (b) TSHA with ground, (c) TSHA with corrugated ground, (d) TSHA with corrugated ground bent downward $\left(R_{d}=15 \mathrm{~mm}\right)$, and (e) TSHA with corrugated ground bent upward $\left(R_{u}=15 \mathrm{~mm}\right)$.

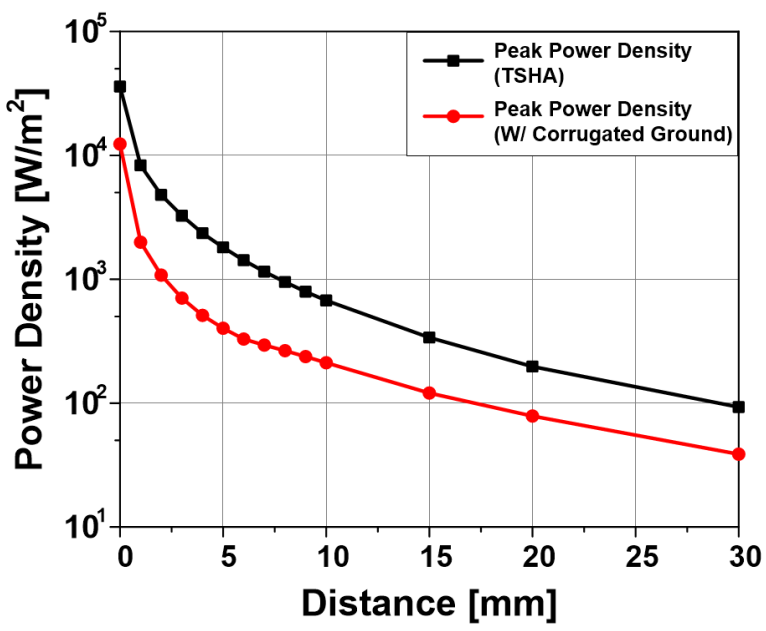

Fig. 4. Simulated power density for different separation distances of an antenna from the body surface.

gated ground maintains a guiding characteristic even if the antenna is bent.

Fig. 4 shows the peak power density on an arbitrary 40 $\mathrm{mm} \times 80 \mathrm{~mm}$ rectangular surface located below the proposed antenna when the input power is $1 \mathrm{~W}$. The peak power density of TSHA with corrugated ground becomes less than that of TSHA in a separation distance range of $0-30$ $\mathrm{mm}$ at $28 \mathrm{GHz}$ because of the suppression of the waves radiating normally to the body surface by the corrugated ground. When the distance is $5 \mathrm{~mm}$, which is a typical separation distance between an antenna and a body, the peak power density of TSHA is $1,808.25 \mathrm{~W} / \mathrm{m}^{2}$ and that of TSHA with corrugated ground is $401.56 \mathrm{~W} / \mathrm{m}^{2}$, which is $22 \%$ of the TSHA peak power density. The maximum allowable input power to satisfy the INCIRP guideline is $13.86 \mathrm{dBm}$ for TSHA with corrugated ground and $6.53 \mathrm{dBm}$ for TSHA.

Fig. 5(a) and (b) show the fabricated textile antenna. The top and bottom ground planes are made of a Shieldex conductive metalized nylon fabric (Zell) with a thickness of 0.1 $\mathrm{mm}$ (surface resistance of $0.02 \Omega / \mathrm{sq}$ ), and the vias for the corrugation and wall of TSHA are made of a Shieldex conductive thread (resistivity of $0.0025 \Omega / \mathrm{cm}^{2}$ ) with a radius of $0.1 \mathrm{~mm}$. Circuitworks conductive epoxy CW2400 was used to attach a $2.92 \mathrm{~mm}(\mathrm{~K})$ connector instead of soldering. The simulated and measured return loss characteristics are shown in Fig. 6(a). The measured results agree well with the simulation. The measured $10 \mathrm{~dB}$ return loss bandwidth is 2,800 $\mathrm{MHz}$ (26.66-29.54 GHz). Fig. 6(b) and (c) show the simulated and measured far-field radiation patterns in the $\mathrm{yz}^{-}$and xy-planes. The measured results are slightly deteriorated because of fabrication errors. The measured peak gain and gain toward the body surface direction $\left(\theta=90^{\circ}\right)$ are $6.54 \mathrm{dBi}$ and $4.14 \mathrm{dBi}$, respectively, at $28 \mathrm{GHz}$. 


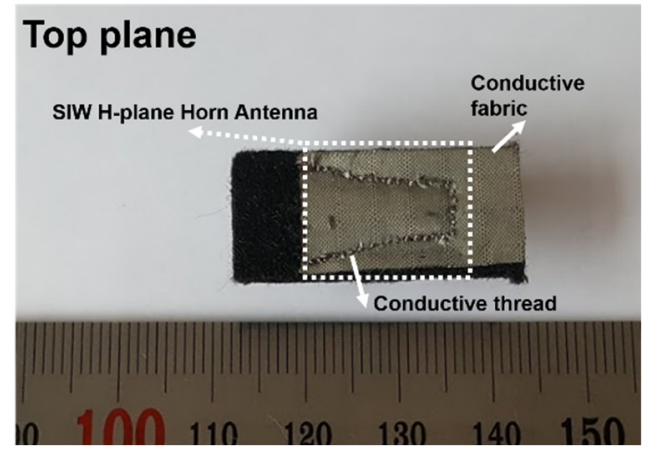

(a)

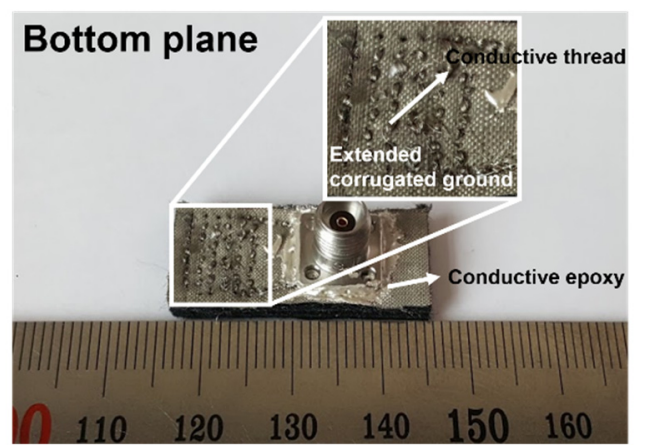

(b)

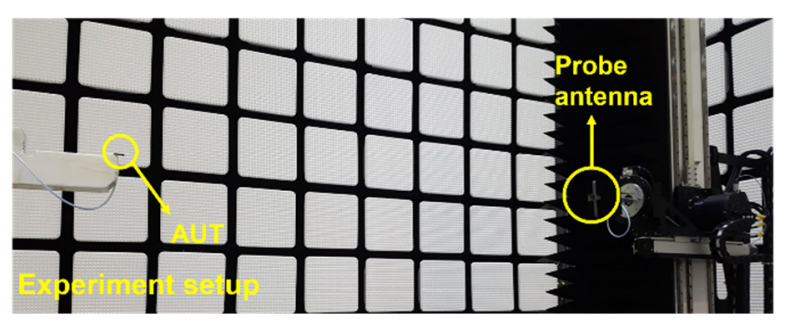

(c)

Fig. 5. Photos of the fabricated antenna and experimental setup: (a) top plane, (b) bottom plane, and (c) experimental setup.

\section{CONCLUSION}

In this paper, an all-textile H-plane SIW horn antenna with corrugated ground for millimeter-wave WBAN applications is proposed. The extended corrugated ground is implemented to guide waves toward the near body surface direction and to suppress radiation toward the human body. The maximum output power to satisfy the ICNIRP guideline is $13.86 \mathrm{dBm}$ when the separation distance between the antenna and the human body is $5 \mathrm{~mm}$. The fact that the proposed antenna has good radiation performance toward the body surface direction and more allowable power than TSHA shows that it has advantages in the millimeter-wave communication environment with higher path loss. The proposed antenna can be easily implemented into wearable devices because it is made completely of textile materials.

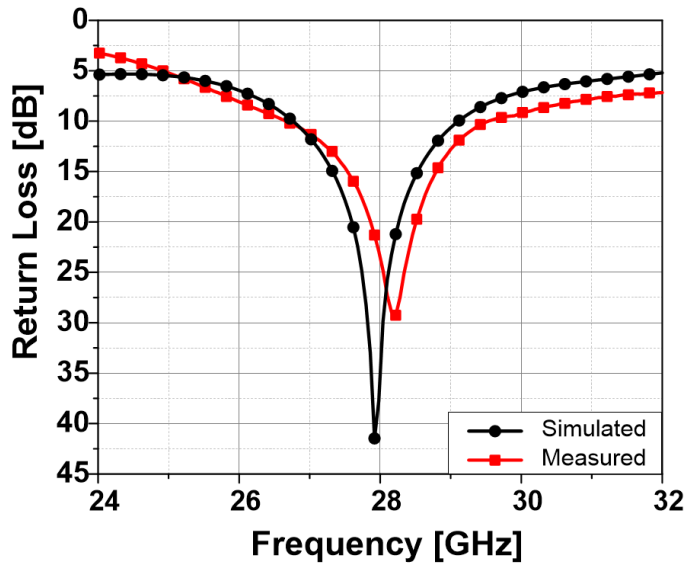

(a)

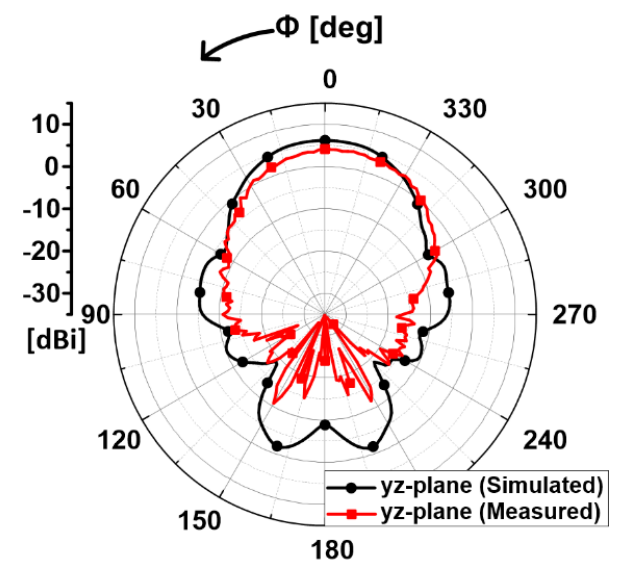

(b)

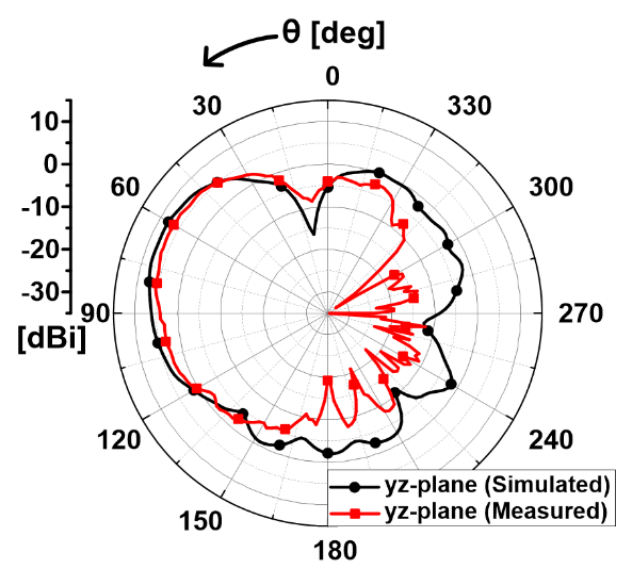

(c)

Fig. 6. Simulated and measured reflection coefficients and radiation pattern results: (a) return loss results, (b) far-field radiation patterns of the proposed antenna in the xy-plane at $28 \mathrm{GHz}$, and (c) far-field radiation patterns of the proposed antenna in the yz-plane at $28 \mathrm{GHz}$.

This work was supported by the National Research Foundation of Korea grant funded by the Korea government (MSIP) (No. 2017R1A2B4002811). 


\section{REFERENCES}

[1] T. S. Rappaport, S. Sun, R. Mayzus, H. Zhao, Y. Azar, $\mathrm{K}$. Wang, et al., "Millimeter wave mobile communications for 5G cellular: It will work!," IEEE Access, vol. 1, pp. 335-349, 2013.

[2] N. Chahat, M. Zhadobov, S. A. Muhammad, L. Le Coq, and R. Sauleau, "60-GHz textile antenna array for bodycentric communications," IEEE Transactions on Antennas and Propagation, vol. 61, no. 4, pp. 1816-1824, 2012.

[3] N. Yoon and C. Seo, "A 28-GHz wideband $2 \times 2$ U-slot patch array antenna," Journal of Electromagnetic Engineering and Science, vol. 17, no. 3, pp. 133-137, 2017.

[4] A. Pellegrini, A. Brizzi, L. Zhang, K. Ali, Y. Hao, X. $\mathrm{Wu}$, et al., "Antennas and propagation for body-centric wireless communications at millimeter-wave frequencies: a review," IEEE Antennas and Propagation Magazine, vol. 55, no. 4, pp. 262-287, 2013.

[5] M. Esquius-Morote, B. Fuchs, J. F. Zurcher, and J. R. Mosig, "Novel thin and compact H-plane SIW horn antenna," IEEE Transactions on Antennas and Propagation, vol. 61, no. 6, pp. 2911-2920, 2013.

[6] Y. Luo and J. Bornemann, "Substrate integrated waveguide horn antenna on thin substrate with back-lobe suppression and its application to arrays," IEEE Antennas and Wireless Propagation Letters, vol. 16, pp. 2622-2625, 2017.

[7] Y. Cai, Y. Zhang, L. Yang, Y. Cao, and Z. Qian, "Design of low-profile metamaterial-loaded substrate integrated waveguide horn antenna and its array applications," IEEE Transactions on Antennas and Propagation, vol. 65, no. 7, pp. 3732-3737, 2017.

[8] IEEE Standard for Safety Levels with Respect to Human Exposure to Radiofrequency Electromagnetic Fields, $3 \mathrm{kHz}$ to $300 \mathrm{GHz}$, IEEE C95.1-1991, 1991.

\section{Seongkyu Lee}

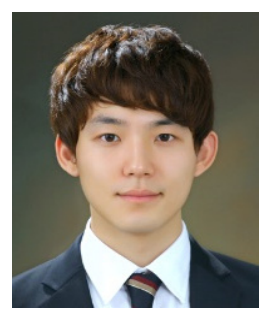

received his B.S. in electronic engineering from Hanyang University in Seoul, Korea, in 2013. He is currently working toward a combined master's and Ph.D. degree in the Department of Electronics and Computer Engineering at Hanyang University in Seoul, Korea. His research interests are RF components including antenna design, wireless communication systems, wireless power transferring, and wireless body area networks.
[9] A. Ahlbom, U. Bergqvist, J. H. Bernhardt, J. P. Cesarini, M. Grandolfo, M. Hietanen, et al., "Guidelines for limiting exposure to time-varying electric, magnetic, and electromagnetic fields (up to $300 \mathrm{GHz}$ )," Health Physics, vol. 74, no. 4, pp. 494-521, 1998.

[10] K. Zhao, Z. Ying, and S. He, "EMF exposure study concerning mmWave phased array in mobile devices for 5G communication," IEEE Antennas and Wireless Propagation Letters, vol. 15, pp. 1132-1135, 2015.

[11] J. Bang and J. Choi, "A SAR reduced mm-wave beamsteerable array antenna with dual-mode operation for fully metal-covered 5G cellular handsets," IEEE Antennas and Wireless Propagation Letters, vol. 17, no. 6, pp. 1118-1122, 2018.

[12] Y. Zhao, Z. Shen, and W. Wu, "Wideband and lowprofile $\mathrm{H}$-plane ridged SIW horn antenna mounted on a large conducting plane," IEEE Transactions on Antennas and Propagation, vol. 62, no. 11, pp. 5895-5900, 2014.

[13] S. Lee and J. Choi, "An all textile H-plane SIW horn antenna with metameterial absorber for millimeter-wave WBAN applications," in Proceedings of 2017 IEEE International Symposium on Antennas and Propagation $\mathcal{E}^{\circ}$ USNC/URSI National Radio Science Meeting, San Diego, CA, 2017, pp. 2653-2654.

[14] J. Tak, S. Lee, and J. Choi, "Design of an all-textile circular patch antenna with corrugated ground for guided wave along the body surface for WBAN applications," Journal of Electromagnetic Waves and Applications, vol. 29, no. 7, pp. 905-924, 2015.

[15] P. J. B. Clarricoats and A. D. Olver, Corrugated Horns for Microwave Antennas. New York, NY: Peter Peregrinus Ltd., 1984.

[16] R. F. Harrington, Time-Harmonic Electromagnetic Fields. New York, NY: McGraw-Hill, 1961.

Jaehoon Choi

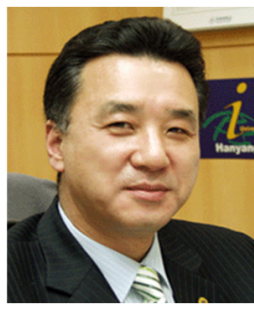

received the B.S. degree from Hanyang University, Korea, and M.S. and Ph.D. degrees from Ohio State University, Ohio, in 1980, 1986, and 1989, respectively. From 1989-1991, he was a research analyst at the Telecommunication Research Center at Arizona State University, Tempe, Arizona. He worked for Korea Telecom as a team leader of the Satellite Communication Division from 1991 to 1995. Since 1995, he has been a professor in the Department of Electronic Engineering at Hanyang University, Korea. He has published more than 200 peer-reviewed journal articles and contributed to numerous conference proceedings. He holds over 100 domestic and international patents. His research interests include antennas, microwave circuit design, and EMC. His current research is mainly focused on the design of compact, multiband antennas for mobile wireless communication and military applications. 